\title{
Deficiency in phytochromobilin biosynthesis enhances heat-stress-induced impairments to the photosynthetic apparatus in tomato
}

\author{
A.J. CRISPIM FILHO ${ }^{*}$, A.C. COSTA2 ${ }^{2}$, F.R.R. ALVES ${ }^{3}$, P.F. BATISTA², A.A. RODRIGUES ${ }^{4}$, \\ S.C. VASCONCELOS FILHO ${ }^{4}$, and K.J.T. NASCIMENTO ${ }^{5}$
}

Departamento de Melhoramento Genético de Plantas, Escola de Agronomia, Universidade Federal de Goiás, Goiânia 74690-900, Goiás, Brazil ${ }^{1}$

Laboratório de Ecofisiologia e Produtividade Vegetal, Instituto Federal Goiano, Rio Verde 75.901-970, Goiás, Brazil

Laboratório de Fisiologia Vegetal, Instituto de Ciências Biológicas, Universidade Federal de Goiás,

Goiânia 74690-900, Goiás, Brazil

Laboratório de Anatomia Vegetal, Instituto Federal Goiano, Rio Verde 75.901-970, Goiás, Brazil ${ }^{4}$

Laboratório de Sementes, Instituto Federal Goiano, Rio Verde 75.901-970, Goiás, Brazil ${ }^{5}$

\begin{abstract}
Plants are continuously exposed to unfavorable environmental conditions, such as heat stress, which negatively affect plant growth and productivity. There is evidence that phytochromes are involved in plant response to different abiotic stresses. We investigated the possible phytochrome-dependent responses to heat stress in photomorphogenic tomato mutants aurea (au, phytochromobilin-deficient, РФB) and high-pigment 1 ( $h \mathrm{pl}$, hyperresponsive to phytochromemediated responses), as well as the wild-type Micro-Tom (MT). In comparison with MT, reductions in photosynthetic rate promoted by a high temperature were more pronounced in $a u$, whereas less pronounced in $h p 1$. All genotypes subjected to the heat stress exhibited adjustments in the capture and dissipation of energy, which were indicated by increases in the initial fluorescence and decreases in the maximum photochemical efficiency of photosystem II (PS II). The effective quantum yield of PS II and the apparent electron transport rate showed greatest alterations in the $a u$ mutant. In addition, heat-triggered anatomical changes occurred in all genotypes but were most conspicuous in the $a u$ mutant, followed by MT. Thus, phytochrome-dependent mechanisms played pivotal roles in the plant responses to the heat stress, and deficiency in phytochromobilin biosynthesis enhanced the heat-induced impairment of photosynthetic performance.
\end{abstract}

Additional key words: aurea mutant, chlorophyll a fluorescence, high-pigment 1 mutant, phytochromes, thermotolerance, Solanum lycopersicum.

\section{Introduction}

In natural or agricultural systems, plants are often exposed to environmental stressors including low rainfall, oscillations of temperature, fluctuations in irradiance, high salinity, and excess of heavy metals, which are unfavorable to their development and growth (Rizhsky et al. 2002, Kreslavski et al. 2007, Soto et al. 2014). These stressful conditions directly hinder a wide range of physiological processes and dramatically reduce crop yield (Doupis et al. 2013, Mutava et al. 2015). Considering the recent climate predictions regarding global warming, heat stress has been highlighted as a threat to agricultural production (Grover et al. 2013,

\footnotetext{
Submitted 11 February 2018, last revision 23 August 2018, accepted 18 September 2018.

Abbreviations: au - aurea; $\mathrm{c}_{\mathrm{i}} / \mathrm{c}_{\mathrm{a}}$ - internal to external $\mathrm{CO}_{2}$ concentration ratio; DDB1 - UV-damaged DNA-binding protein 1; $\mathrm{E}$ - transpiration rate; ETR - apparent electron transport rate; $\mathrm{F}_{\mathrm{o}}$ - initial fluorescence; $\mathrm{F}_{\mathrm{v}} / \mathrm{F}_{\mathrm{m}}$ - variable to maximum fluorescence ratio (maximum photochemical efficiency of photosystem II); $\mathrm{F}_{\mathrm{v}}{ }^{\prime} / \mathrm{F}_{\mathrm{m}}{ }^{\prime}$ - effective quantum yield of photosystem II; $\mathrm{g}_{\mathrm{s}}$ - stomatal conductance; hpl - high-pigment 1; MT - Micro-Tom; NPQ - non-photochemical quenching; $\mathrm{P}_{\mathrm{N}}$ - net photosynthetic rate; PФB phytochromobilin; PS II - photosystem II; Rubisco - ribulose-1,5-bisphosphate carboxylase/oxygenase.

Acknowledgements: The authors would like to thank the financial support from the Coordenação de Aperfeiçoamento Pessoal de Nível Superior (CAPES), the Conselho Nacional de Desenvolvimento Científico e Tecnológico (CNPq), the Financiadora de Estudos e Projetos (Finep), the Fundação de Amparo à Pesquisa do Estado de Goiás (FAPEG), and the Instituto Federal Goiano, Campus Rio Verde. The authors are also grateful to Dr. Lázaro E. P. Peres (Escola Superior de Agricultura Luiz de Queiroz, ESALQ-USP) and Dr. Rogério F. Carvalho (Universidade Estadual Paulista Júlio de Mesquita Filho, UNESP) for providing the mutant tomato seeds.

*Author for correspondence; e-mail: ailtonjcf@gmail.com; alan.costa@ifgoiano.edu.br
} 
Mathur et al. 2014). Heat may cause oxidative stress from increased production of reactive oxygen species. Their excess can lead to protein denaturation, enzyme inactivation, and decreased photosynthesis (Ingraham et al. 1985, Kreslavski et al. 2007, Allakhverdiev et al. 2008, Lubovská et al. 2014, Sajid et al. 2018)).

Phytochromes are photoreceptors, which are composed of an apoprotein associated with a chromophore (phytochromobilin in higher plants). They are involved in the control of germination, plant elongation, flowering, shade tolerance (Possart et al. 2014), biosynthesis of enzymes in the photosynthetic apparatus (McCormac et al. 2001, Moon et al. 2008), and stomatal density (Boccalandro et al. 2009, Melo et al. 2011). These photoreceptors also play roles in cellular signaling plant defense against abiotic stresses, including high and low temperatures, water deficit, and salinity (Carvalho et al. 2011a, Alves et al. 2016). Phytochromes activate the expression of genes related to the biosynthesis of heat shock protein and control stomatal conductance, both of which may increase plant heat tolerance (Boccalandro et al. 2003, Zhou et al. 2014). Considering these functions, studying the role of phytochromes in plant responses at high temperatures is a promising strategy to improve the yield of agricultural crops exposed to harsh environmental conditions (Zhang et al. 2013).

Photomorphogenic mutants, such as the aurea (au) and high-pigment 1 (hpl) tomato mutants, have been used in studies of phytochrome-mediated physiological processes. The au mutant is deficient in phytochromobilin (PФB) biosynthesis, which impairs the formation of functional phytochromes (Muramoto et al. 2005). Consequently, the au mutants present a distinct phenotype of elongated hypocotyls and yellow to lightgreen leaves due to a lower content of anthocyanins and chlorophylls (Terry and Kendrick 1996). The hpl presents a mutation in UV-damaged DNA-binding protein 1 (DDB1), one of the repressors of the phytochrome signaling pathway, which results in hyperresponsiveness to high irradiance. Measurably, the $h p 1$ mutants present dark-green leaves and fruits as well as a higher activity of light-dependent enzymes such as phenyalanine ammonia lyase and nitrate reductase (Goud et al. 1991, Goud and Sharma 1994, Peters et al. 1998, Liu et al. 2004).

These mutations were introgressed in a miniature tomato cultivar Micro-Tom (MT), which is used as a model in genetic and physiological studies due to its relatively short life cycle and the convenience of cultivation (Carvalho et al. 2011b). Elucidating the physiological effects related to phytochrome could lead to the development of plant cultivars or lineages with improved yield under stressful conditions. Therefore, the aim of this work was to assess the influence of phytochrome-dependent responses on the photosynthetic process of the photomorphogenic tomato mutants subjected to heat stress.

\section{Material and methods}

Plant growth and heat stress treatment: Tomato (Solanum lycopersicum L.) seeds from the MT wild-type cultivar and the $a u$ and $h p l$ mutants were sown in trays containing Bioplant $^{\mathbb{R}}$ substrate (Nova Ponte, Minas Gerais, Brazil). During the germination period, the seedlings were grown in a greenhouse under controlled conditions of temperature $\left(24-27{ }^{\circ} \mathrm{C}\right)$, air humidity $(60-80 \%)$, photoperiod $(13 \mathrm{~h})$, and irradiance $(550 \pm 50$ $\left.\mu \mathrm{mol} \mathrm{m} \mathrm{m}^{-2} \mathrm{~s}^{-1}\right)$. After $17 \mathrm{~d}$, the seedlings of a similar size and vigor were transplanted into $0.5-\mathrm{dm}^{3}$ pots containing red dystroferric latosol (Oxisol) and sand at a 2:1 (v/v) ratio. A fertilizer mix was added to the substrate to supply crop requirements. Two weeks after transplanting, the plants were initially acclimated in a growth chamber (BOD, LIMATEC LT 320TFP-I, Cruz das Almas, Bahia, Brazil) with a mean temperature of $25^{\circ} \mathrm{C}$, a $75 \%$ relative humidity, a 12-h photoperiod, and mean irradiance of 150 $\mu \mathrm{mol} \mathrm{m} \mathrm{m}^{-2} \mathrm{~s}^{-1}$ for 5 days. These conditions reduced the possible occurrence of photo-oxidative damage induced by an excessive irradiance combined with heat stress, as proposed by Ferreira-Silva et al. (2011).

After the acclimation period, the plants were separated into two groups comprising four plants of each genotype. Group 01 was maintained under the same initial conditions in the growth chamber. Group 02 was maintained in another growth chamber and subjected to a

temperature of $42 \pm 2{ }^{\circ} \mathrm{C}$ for 7 consecutive days by gradually increasing the temperature to $42{ }^{\circ} \mathrm{C}$ from 11:00 to $12: 00$ and decreasing to $25^{\circ} \mathrm{C}$ from 17:00 to $19: 00$.

Leaf gas exchange, chlorophyll $a$ fluorescence, and leaf water potential: Leaf gas exchange and chlorophyll $a$ fluorescence were measured at 1, 3, 5, and 7 days after the heat treatment, and images of chlorophyll $a$ fluorescence were obtained at the last evaluation time. The net photosynthetic rate $\left[\mathrm{P}_{\mathrm{N}}, \mu \operatorname{mol}\left(\mathrm{CO}_{2}\right) \mathrm{m}^{-2} \mathrm{~s}^{-1}\right]$, transpiration rate $\left[\mathrm{E}, \operatorname{mmol}\left(\mathrm{H}_{2} \mathrm{O}\right) \mathrm{m}^{-2} \mathrm{~s}^{-1}\right]$, stomatal conductance $\left[\mathrm{g}_{\mathrm{s}}, \operatorname{mol}\left(\mathrm{H}_{2} \mathrm{O}\right) \mathrm{m}^{-2} \mathrm{~s}^{-1}\right]$, and ratio of internal to external $\mathrm{CO}_{2}\left(\mathrm{c}_{\mathrm{i}} / \mathrm{c}_{\mathrm{a}}\right)$ were determined in the fourth leaf from the base. Measurements were performed using a portable infrared gas analyzer (LI-6400XTR, LI-COR, Lincoln, Nebraska, USA) between 08:00 and 11:00 at an irradiance of $1000 \mu \mathrm{mol} \mathrm{m} \mathrm{m}^{-2} \mathrm{~s}^{-1}$, a $\mathrm{CO}_{2}$ concentration of $400 \mu \mathrm{mol} \mathrm{mol}{ }^{-1}$, a block temperature of $25 \pm 1{ }^{\circ} \mathrm{C}$, and a $75 \%$ relative humidity.

The chlorophyll a fluorescence parameters were measured on the same leaves. For the assessments, leaves were dark-adapted to achieve complete opening the reaction centers (all electron carriers) with a minimum heat loss. Variable fluorescence $\left(\mathrm{F}_{\mathrm{v}}\right)$ was a difference between maximum fluorescence $\left(\mathrm{F}_{\mathrm{m}}\right)$ and initial fluorescence $\left(\mathrm{F}_{\mathrm{o}}\right)$; maximum photochemical efficiency of 
photosystem II (PS II) was calculated as $\mathrm{F}_{\mathrm{v}} / \mathrm{F}_{\mathrm{m}}$ (Genty et al. 1989).

Variables from the slow phase of fluorescence induction were then obtained by applying actinic light to determine fluorescence of light-adapted leaves $\left(\mathrm{F}_{\mathrm{o}}{ }^{\prime}\right)$ before the saturating pulse. Maximum fluorescence of light-adapted leaves $\left(\mathrm{F}_{\mathrm{m}}{ }^{\prime}\right)$ was used to calculate effective quantum yield of PS II as $\mathrm{F}_{\mathrm{v}}{ }^{\prime} / \mathrm{F}^{\prime}=\left(\mathrm{F}_{\mathrm{m}}{ }^{\prime}-\mathrm{F}_{\mathrm{o}}{ }^{\prime}\right) / \mathrm{F}_{\mathrm{m}}{ }^{\prime}$ (Genty et al. 1989). The $\mathrm{F}_{\mathrm{v}}{ }^{\prime} / \mathrm{F}_{\mathrm{m}}{ }^{\prime}$ was also used to estimate apparent electron transport rate (ETR) as follows: ETR = $\mathrm{F}_{\mathrm{v}}{ }^{\prime} / \mathrm{F}_{\mathrm{m}}{ }^{\prime} \times$ photosynthetic photon flux density $\times 0.5 \times$ leaf absorptivity coefficient [ $\mu \mathrm{mol}\left(\right.$ electrons) $\mathrm{m}^{-2} \mathrm{~s}^{-1}$ ] (Kalaji et al. 2014). Non-photochemical quenching (NPQ) was calculated as NPQ $=\left(\mathrm{F}_{\mathrm{m}}-\mathrm{F}_{\mathrm{m}}{ }^{\prime}\right) / \mathrm{F}_{\mathrm{m}}{ }^{\prime}$ (Bilger and Björkman 1990).

The $F_{o}, F_{v} / F_{m}, F_{v}{ }^{\prime} / F_{m}{ }^{\prime}, E T R$, and NPQ were also measured using an imaging fluorometer (Imaging-PAM, Heinz Walz, Effeltrich, Germany) to confirm the chlorophyll $a$ fluorescence results obtained by the LI-6400XTR. The imaging fluorometer can be used to map the fluorescence parameters in a larger area than that obtained by the LI-6400XTR, thus enabling assessment of the alterations throughout the leaf. To verify whether the water status was affected by heat stress, the leaf water potential of the plants was assessed before dawn (between 04:00 and 06:00) on the first and last days of the heat treatment using the pressure bomb technique (Scholander et al. 1965).

Content of chlorophylls and carotenoids: The content of photosynthetic pigments was determined on the last day of the heat treatment according to the method proposed by Meneguelli-Souza et al. (2016). The values were calculated using equations proposed by Wellburn et al. (1997).

\section{Results}

Regardless of genotype, $\mathrm{P}_{\mathrm{N}}$ decreased after 3 days at $42{ }^{\circ} \mathrm{C}$ compared to the control at $25{ }^{\circ} \mathrm{C}$ (a significant interaction $\mathrm{G} \times \mathrm{T} \times \mathrm{D}$ ) (Fig. $1 A, B, C$; Table 1 Suppl.). The negative effect of the high temperature on $\mathrm{P}_{\mathrm{N}}$ was reduced in the $h p l$ mutant compared to the other genotypes. Usually, the mutant $a u$ showed reductions that were more pronounced in $\mathrm{P}_{\mathrm{N}}$ when subjected to the heat stress compared to the $h p l$ and MT genotypes during the evaluation period. The respective decreases compared to the control counterparts were 27, 18, and $50 \%$ for genotypes MT, $h p l$, and $a u$ subjected to $42{ }^{\circ} \mathrm{C}$ for $7 \mathrm{~d}$.

Changes in $\mathrm{P}_{\mathrm{N}}$ were coupled with alterations in $\mathrm{g}_{\mathrm{s}}$ and $\mathrm{E}$ in $\mathrm{MT}$ and the $h p 1$ mutant (a significant interaction $\mathrm{G} \times$ $\mathrm{T} \times \mathrm{D})$ (Fig. $1 D, E, F$; Table 1 Suppl.). Compared to the controls, $g_{s}$ increased by 83 and $193 \%$ in MT and the $h p 1$ mutant when subjected to $42{ }^{\circ} \mathrm{C}$ for 1 day, respectively. The E increased by 64 and $115 \%$ under these conditions, respectively. Generally, the increases in $g_{s}$ and $E$ triggered by the heat stress decreased progressively and
Anatomical analyses: To characterize the possible anatomical changes, leaf samples of the first node were collected on the last day of the heat treatment and stored for $24 \mathrm{~h}$ in a Karnovsky fixative (Karnovsky 1965). The plant material was next dehydrated in a series of increasing ethanol concentrations and then pre-infiltrated and infiltrated in Historesin (Leica, Nussloch, Germany) according to the manufacturer's recommendations. For histochemical assays, samples were cross-sectioned at 5 $\mu \mathrm{m}$ in a rotary microtome (model 1508R, Biobase, Shandong, China) and stained with toluidine blue $(0.05 \%$, $\mathrm{m} / \mathrm{v}$, in $0.1 \mathrm{M}$ phosphate buffer, $\mathrm{pH}$ 6.8) (O’Brien et al. 1964). Observations were performed using an Olympus microscope (model BX61, Tokyo, Japan) with the bright field option.

Statistical analyses: Experiments were carried out in a completely randomized design with 4 replicates (a total of 24 experimental units). Data were subjected to an analysis of variance $(A N O V A)$ and the Tukey test at a $5 \%$ probability using the SISVAR software (v. 5.6). The following experimental designs were considered for ANOVA: the first was a $3 \times 2 \times 4$ factorial design consisting of 3 genotypes (MT, $h p l$, and $a u$ ), 2 temperatures $\left(25\right.$ and $\left.42{ }^{\circ} \mathrm{C}\right)$, and 4 evaluation times $(1,3,5$, and 7 days of heat treatment) for the leaf gas exchange and chlorophyll $a$ fluorescence. The second was a $3 \times 2$ factorial design for the content of photosynthetic pigments, anatomical changes, and image of chlorophyll $a$ fluorescence (3 genotypes and 2 temperatures). The final design was a $3 \times 2 \times 2$ arrangement for the leaf water potential ( 3 genotypes, 2 temperatures), and 2 evaluation times ( 1 and 7 days of heat treatment).

were maintained in MT and the $h p 1$ mutant from 3 days of the heat treatment onwards (Fig. 1D,E,G,H). Surprisingly, in the au mutant, $\mathrm{g}_{\mathrm{s}}$ and E were unchanged in response to the heat stress regardless of evaluation time (Fig. $1 F, I$ ).

Additionally, the heat stress increased $\mathrm{c}_{\mathrm{i}} / \mathrm{c}_{\mathrm{a}}$ in MT and in the $h p l$ mutant during the evaluation period (Fig. $1 J, K$ ). The $\mathrm{c}_{\mathrm{i}} / \mathrm{c}_{\mathrm{a}}$ increased only in the $a u$ mutant when it was subjected to $42{ }^{\circ} \mathrm{C}$ for 7 days compared to the control (Fig. $1 L$ ). Therefore, the $h p l$ mutant generally displayed a higher photosynthetic performance (higher values of $\mathrm{P}_{\mathrm{N}}$, $\mathrm{g}_{\mathrm{s}}$, and $E$ ) than the other two genotypes even under heat stress conditions (Fig. 1 and Table 1 Suppl.).

The values of $F_{v} / F_{m}, F_{v}^{\prime} / F_{m}{ }^{\prime}$, ETR, and NPQ were usually lower in all the genotypes at $42{ }^{\circ} \mathrm{C}$ compared to their non-stressed counterparts (a significant interaction $\mathrm{G} \times \mathrm{T} \times \mathrm{D}$ ) regardless of evaluation time (Fig. $2 D-O$ and Table 1 Suppl.). Conversely, $F_{o}$ was higher in the genotypes under the heat stress (Fig. 2A,B,C). Higher 
decreases in the variables of chlorophyll $a$ fluorescence were induced by the high temperature in the $a u$ mutant compared to the other genotypes (Fig. 2 and 3). On the third day of the high temperature treatment and onward, there were slightly lower reductions in the quantum yield of PS II in the hpl mutant compared to MT (represented by $\mathrm{F}_{\mathrm{v}} / \mathrm{F}_{\mathrm{m}}$ and $\left.\mathrm{F}_{\mathrm{v}}{ }^{\prime} / \mathrm{F}_{\mathrm{m}}{ }^{\prime}\right)$. Compared to the control counterparts, $\mathrm{F}_{\mathrm{v}} / \mathrm{F}_{\mathrm{m}}$ showed significant reductions of 12,8 , and $27 \%$ in MT, $h p l$, and $a u$ when treated for $7 \mathrm{~d}$ at $42{ }^{\circ} \mathrm{C}$, respectively. The $\mathrm{F}_{\mathrm{v}}{ }^{\prime} / \mathrm{F}_{\mathrm{m}}{ }^{\prime}$ showed significant reductions of 24,15 , and $53 \%$ (Fig. $2 G-L$ ).

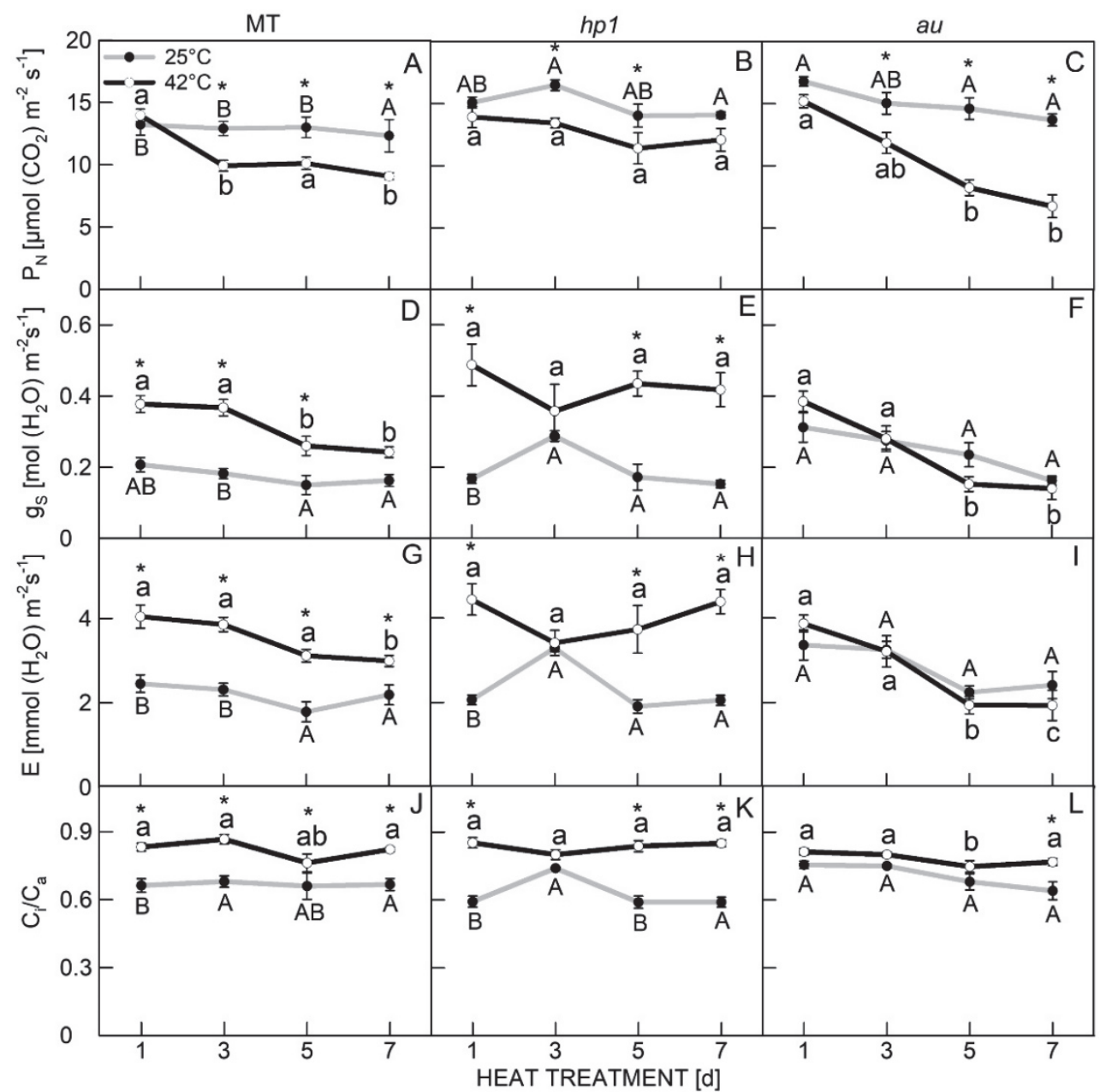

Fig. 1. Net photosynthetic rate $\left(\mathrm{P}_{\mathrm{N}} ; A, B, C\right)$, stomatal conductance $\left(\mathrm{g}_{\mathrm{s}} ; D, E, F\right)$, transpiration rate $(\mathrm{E} ; G, H, \mathrm{I})$ and internal to external $\mathrm{CO}_{2}$ ratio $\left(\mathrm{c}_{i} / \mathrm{c}_{\mathrm{a}} ; J, K, L\right)$ in tomato mutants aurea $(a u)$ and high-pigment $1(h p 1)$, and in the wild type Micro-Tom (MT) subjected to 25 or $42{ }^{\circ} \mathrm{C}$ for $1,3,5$, and $7 \mathrm{~d}$. Means \pm SEs, $n=4$. Within each day, there are no significant differences among genotypes in means that are followed by the same uppercase letter at $25{ }^{\circ} \mathrm{C}$ and lowercase letter for the treatment at $42{ }^{\circ} \mathrm{C}$, and means that are not followed by an asterisk between temperatures based on the Tukey test at a $5 \%$ probability.

Usually, the heat stress for 7 days increased $\mathrm{F}_{\mathrm{o}}$ by 29 , 42, and $144 \%$ in MT, $h p 1$, and $a u$,respectively, compared to their controls (Fig. $2 A, B, C$ ). The lowest impairments in the photosynthetic performance were observed in the hpl mutant, which is evidenced by the lowest decreases in $\mathrm{F}_{\mathrm{v}} / \mathrm{F}_{\mathrm{m}}, \mathrm{F}_{\mathrm{v}}{ }^{\prime} / \mathrm{F}_{\mathrm{m}}{ }^{\prime}$, and ETR (Fig. 3 B1-B6, C1-6, and D1-6). Irrespective of genotype, the high temperature decreased NPQ particularly in the $a u$ mutant (Fig. 3 E1-6). In non-stressful conditions, the variables of chlorophyll $a$ fluorescence $\left(\mathrm{F}_{\mathrm{o}}, \mathrm{F}_{\mathrm{v}} / \mathrm{F}_{\mathrm{m}}, \mathrm{F}_{\mathrm{v}}{ }^{\prime} / \mathrm{F}_{\mathrm{m}}{ }^{\prime}, \mathrm{ETR}\right.$, and NPQ) did not usually differ among the genotypes regardless of evaluation time, with the exception of the au mutant, which had a lower $\mathrm{F}_{\mathrm{o}}$ (Fig. 2).
The hpl mutant showed a lower water leaf potential than the $a u$ mutant and a similar water potential to MT irrespective of the temperature treatments and evaluation time (a non-significant interaction $\mathrm{G} \times \mathrm{T} \times \mathrm{D}$ ), as shown in Fig. 4.

No significant relationship was observed between temperatures and genotypes for chloroplastic pigments (Table 1 Suppl.). However, the au mutant exhibited a lower content of chlorophyll $a$, chlorophyll $b$, and carotenoids compared to the $h p l$ mutant and MT (Fig. 5A,C,E). Irrespective of genotype, there were a lower content of chlorophyll $a$ and chlorophyll $b$ and a lower chlorophyll $a / b$ ratio in the plants under the heat 


\section{A.J. CRISPIM FILHO et al.}

stress (Fig. 5B,D,F).

Irrespective of genotype, the heat stress changed the cellular structure of the mesophyll (Fig. 6). Heattriggered anatomical changes at $42{ }^{\circ} \mathrm{C}$ were most prominent in the au mutant followed by the MT genotype These genotypes exhibited disorganization of the parenchyma cells, electrolyte leakage, and mesophyll retraction (Fig. 6B,F).

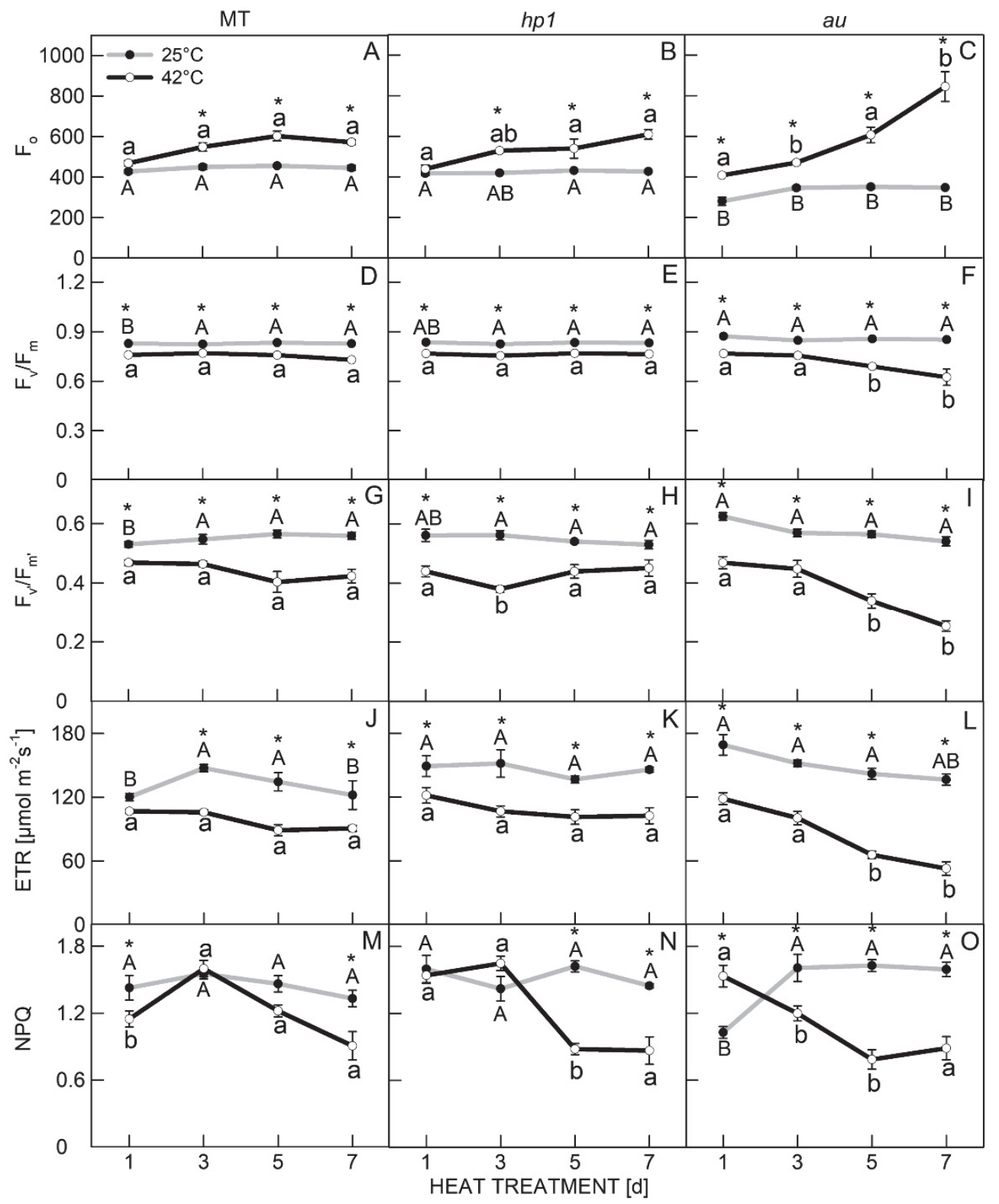

Fig. 2. An initial chlorophyll $a$ fluorescence $\left(\mathrm{F}_{\mathrm{o}}, A, B, C\right)$, maximum photochemical efficiency of photosystem II (PS II) ( $\mathrm{F}_{\mathrm{v}} / \mathrm{F}_{\mathrm{m}}$; $D, E, F)$, effective quantum yield of PS II $\left(\mathrm{F}_{\mathrm{v}}{ }^{\prime} / \mathrm{F}_{\mathrm{m}}{ }^{\prime} ; G, H, I\right)$, apparent electron transport rate (ETR; $\left.J, K, L\right)$, and non-photochemical quenching (NPQ; $M, N, O)$ in the tomato mutants aurea (au) and high-pigment $1(\mathrm{hpl})$ and wild type Micro-Tom (MT) subjected to 25 or $42{ }^{\circ} \mathrm{C}$ for $1,3,5$, and 7 days. Means \pm SEs, $n=4$. Within each day, there are no significant differences between genotypes in means that are followed by the same uppercase letter at $25{ }^{\circ} \mathrm{C}$ and lowercase letter for the treatment at $42{ }^{\circ} \mathrm{C}$, and means that are not followed by an asterisk between temperatures based on the Tukey test at a $5 \%$ probability.

\section{Discussion}

This study investigated the role of phytochromedependent responses in plant tolerance to high temperature using tomato photomorphogenic mutants as models. Such approach provided evidence that phytochrome plays a pivotal role in plant responses to heat stress, which was indicated by an enhanced 
photosynthetic dysfunction observed in the aurea РФВdeficient mutant. Although the heat stress negatively affected the leaf gas exchange in all of the genotypes, the impairments were less pronounced for the $h p 1$ mutant, which is hyperresponsive to irradiance. A similar physiological performance has been reported in other plant species subjected to high temperatures (Galmés et al. 2015).

The increased $\mathrm{g}_{\mathrm{s}}$ and $\mathrm{E}$ observed in the $\mathrm{hpl}$ mutant in comparison to MT also contributed to the better photosynthetic performance of this mutant at the high temperature (Fig. 1E,H). Increased $\mathrm{E}$ is an efficient mechanism for heat dissipation and maintaining adequate leaf temperatures and so mitigating damage induced by heat stress (Rizhsky et al. 2002, Lubovská et al. 2014). The effective heat dissipation in the $h p l$ mutant may be related to its high stomatal density (Boccalandro et al. 2009, Melo et al. 2011). There is also evidence that phytochrome-dependent responses are positively related to both a high stomatal density and a high transpiration (Boccalandro et al. 2003, Schittenhelm et al. 2004).

The deficiency in PФВ biosynthesis in the au mutant affected the stomatal aperture (Fig. 1F). This indicates that functional phytochromes are important in the

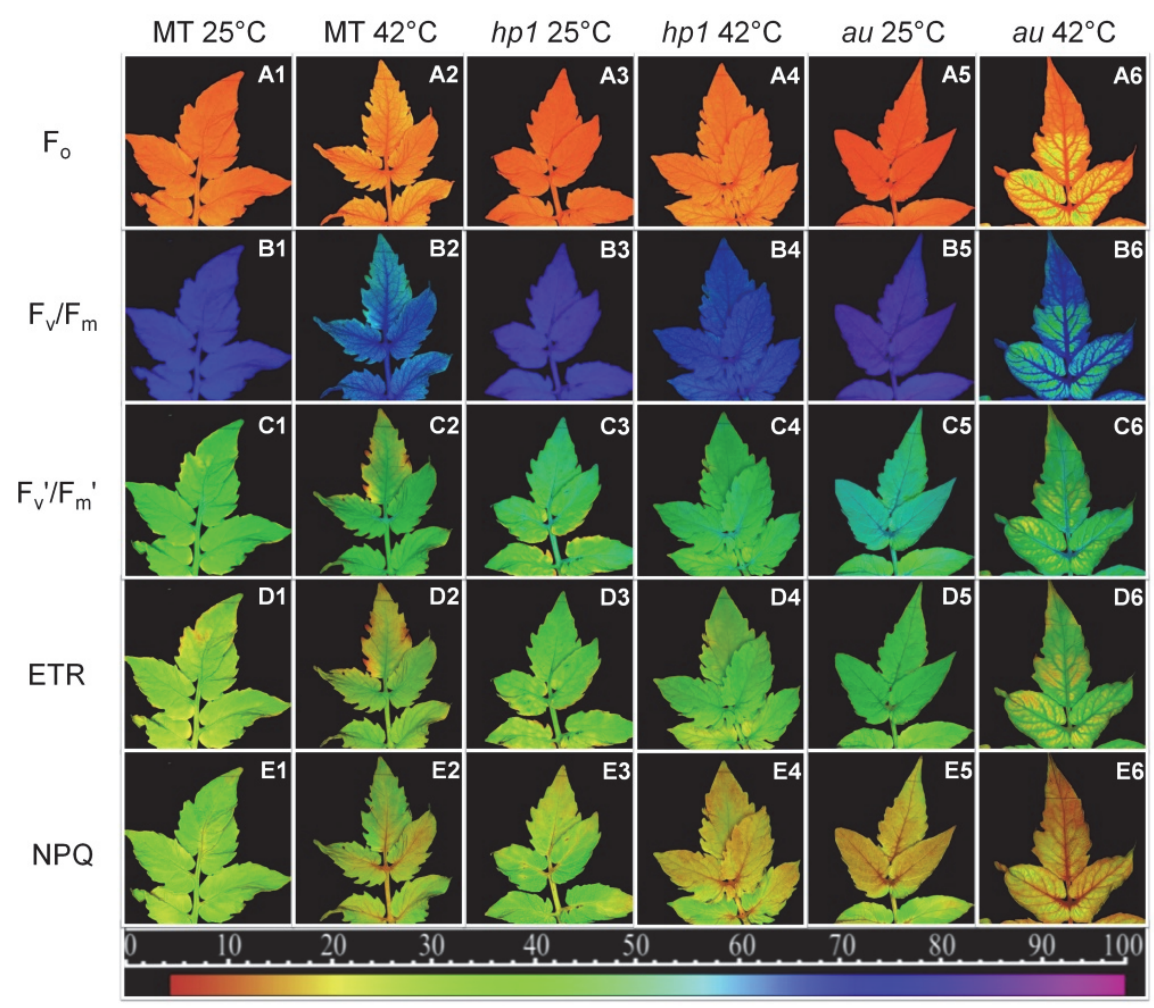

Fig. 3. Images of chlorophyll $a$ fluorescence $\left(\mathrm{F}_{\mathrm{o}} ; A 1-\sigma\right)$, maximum photochemical efficiency of photosystem II (PS II) ( $\mathrm{F}_{\mathrm{v}} / \mathrm{F}_{\mathrm{m}} ;$ B1-б), effective quantum yield of PS II ( $\left.\mathrm{Fv}_{\mathrm{v}}{ }^{\prime} / \mathrm{Fm}^{\prime} ; C 1-6\right)$, apparent electron transport rate (ETR; D1-Ø), and non-photochemical quenching (NPQ, E1-6) in the tomato mutants aurea (au) and high-pigment 1 ( $h p 1)$ and wild type Micro-Tom (MT) subjected to 25 or $42^{\circ} \mathrm{C}$ for 7 days.

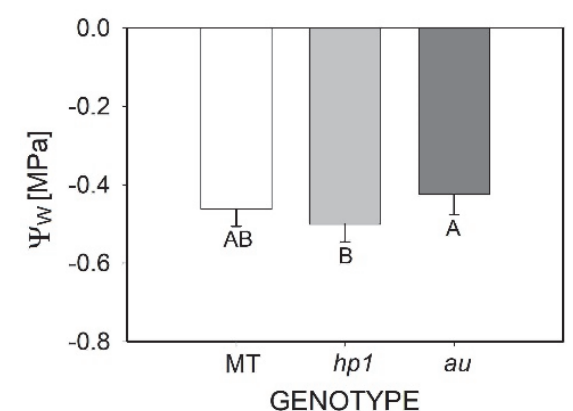

Fig. 4. Water leaf potential in the tomato mutants aurea (au) and high-pigment 1 (hpl) and wild type Micro-Tom (MT) regardless the temperature and evaluation times. Means \pm SEs, $n=16$. Means that are followed by the same letter are not significantly different (at a $5 \%$ probability; Tukey test). responses of plants to high temperatures via the regulation of stomatal opening. All the genotypes had a similar water status under the high temperature, which means that the changes observed in $\mathrm{g}_{\mathrm{s}}$ were strictly related to the high temperature (Fig. 4). Melo et al. (2011) reported that the au mutant usually displays an unchanged stomatal density compared to MT, which corroborates the hypothesis that stomatal opening for heat dissipation is mediated by phytochromes (Wang et al. 2010, Chen et al. 2012). Thus, the lower gene expression of phytochromes stemming from the deficiency in РФВ synthase in the au mutant (Carvalho et al. 2011b, Bianchetti et al., 2017) is linked to a higher thermosensitivity due to a decrease in heat dissipation.

In addition to the physiological damage, the heat stress caused a slight damage in the palisade and spongy 
parenchyma cells in the $h p l$ mutant in comparison to the other genotypes (Fig. 6D). The stability of cell structure is strongly related to plant thermotolerance and can be used to assess a putative heat tolerance (Latif and Mohamed 2016). Heat stress can damage membranes and cause rupture in the cell walls of mesophyll tissue. This results in solute leakage and the collapse of parenchyma cells (Zhang et al. 2009), which was particularly evident in the au mutant.

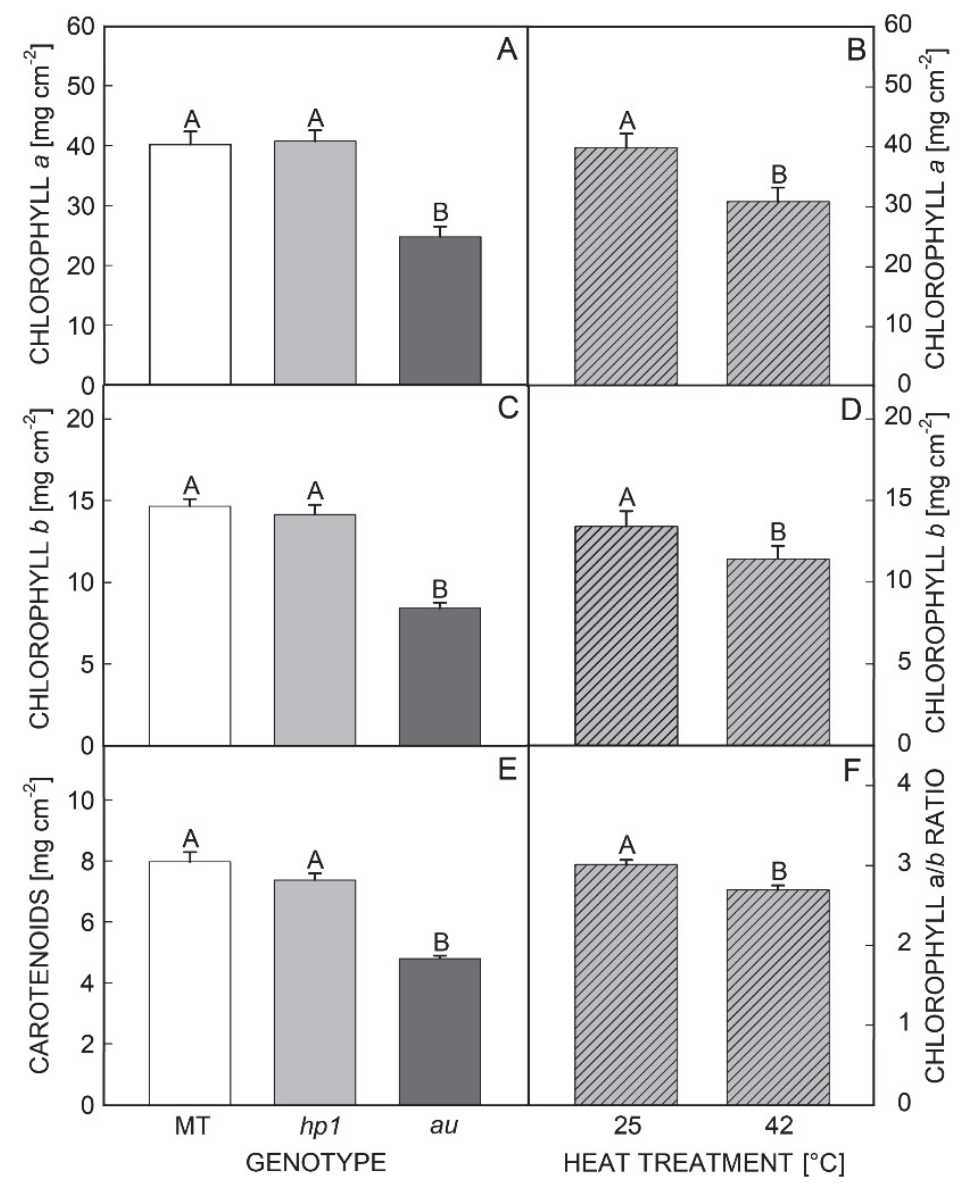

Fig. 5. Content of chlorophyll $a(A)$, chlorophyll $b(C)$, and carotenoids $(E)$ in the tomato mutants aurea (au) and high-pigment 1 $\left(\mathrm{hpl}\right.$ ) and wild type Micro-Tom (MT) regardless the temperature. The effect of temperatures of 25 or $42{ }^{\circ} \mathrm{C}$ for 7 days on the content of chlorophyll $a(B)$, chlorophyll $b(D)$, and chlorophyll $a / b$ ratio $(F)$ regardless the genotype. Means \pm SEs, $n=8$ for genotypes and 12 for temperature. Means that are followed by the same uppercase letter are not significantly different based on the Tukey test at a $5 \%$ probability.

The content of photosynthetic pigments is strongly influenced by phytochromes (Khudyakova et al. 2017). Thus, the lower content of photosynthetic pigments in the au mutant could also be related to its higher heat sensitivity because of a decreased energy dissipation through either photochemical or non-photochemical pathways (Fig. 5A,C,E) (Merzlyak and Solovchenko 2002). Both pathways are involved in the dissipation of excess of radiation (Merzlyak and Solovchenko 2002, Krüger et al. 2014). The reduction observed in the chlorophyll $a / b$ ratio induced by the heat stress corroborates with findings that chlorophyll $a$ is more heat sensitive than chlorophyll $b$ (Murchie and Horton 1997).

The high $\mathrm{c}_{\mathrm{i}} / \mathrm{c}_{\mathrm{a}}$ ratios observed in the MT and au mutant were probably due to a lower efficiency in $\mathrm{CO}_{2}$ assimilation caused by the high temperature (Fig. $1 J, L$ ). This may have resulted from a reduction in the carboxylation activity of ribulose-1,5-bisphosphate carboxylase/oxygenase (Rubisco) due to an increased photorespiration (Mathur et al. 2014, Sharma et al. 2016). Another reason could be the denaturation of Rubisco activase due to heat stress (Grover et al. 2013). Moreover, high temperatures greatly compromise the expression of genes encoding for the synthesis of proteins involved in the Calvin cycle including Rubisco and Rubisco activase (Crafts-Brandner and Salvucci 2000, Salvucci and CraftsBrandner 2004, Allakhverdiev et al. 2008). In contrast, the increased $\mathrm{CO}_{2}$ content in the substomatal cavity recorded in the $h p l$ mutant can be attributed to the higher $\mathrm{g}_{\mathrm{s}}$ and heat dissipation rather than a lower efficiency of the Calvin cycle enzymes (Fig $1 K$ ).

The tomato plants subjected to the heat stress exhibited clear adjustments in the capture and dissipation of energy as indicated by the increases in $F_{o}$ and 
decreases in $F_{\mathrm{v}} / \mathrm{F}_{\mathrm{m}}, \mathrm{F}_{\mathrm{v}}{ }^{\prime} / \mathrm{F}_{\mathrm{m}}{ }^{\prime}$, and ETR, which were remarkably altered in the $a u$ mutant (Fig. 2). The changes in fluorescence parameters are an efficient tool for distinguishing heat stress tolerant genotypes (Allakhverdiev et al. 2008). A loss of thylakoid membrane integrity is most likely responsible for a loss in physiological performance in genotypes at high temperature indicated by concurrent reductions in leaf gas exchange and chlorophyll $a$ fluorescence (Allakhverdiev et al. 2008, Teskey et al. 2014, Gerganova et al. 2016). Normal functioning PS II and the integrity of thylakoid membranes play a key role in the adaptation of plants to stress (Kreslavski et al. 2007). In our study, the disruption in the PS II light absorption complexes evidenced by decreases in $F_{v} / F_{m}$ accounted for the reduction in the effective capacity of electron transport in PS II, which was confirmed by reductions of ETR and $\mathrm{F}_{\mathrm{v}}{ }^{\prime} / \mathrm{F}_{\mathrm{m}}{ }^{\prime}$ and hence impaired $\mathrm{P}_{\mathrm{N}}$ in all genotypes. However, these responses were less evident in the hpl mutant and wild type suggesting the involvement of functional phytochromes in the plant tolerance to heat stress.

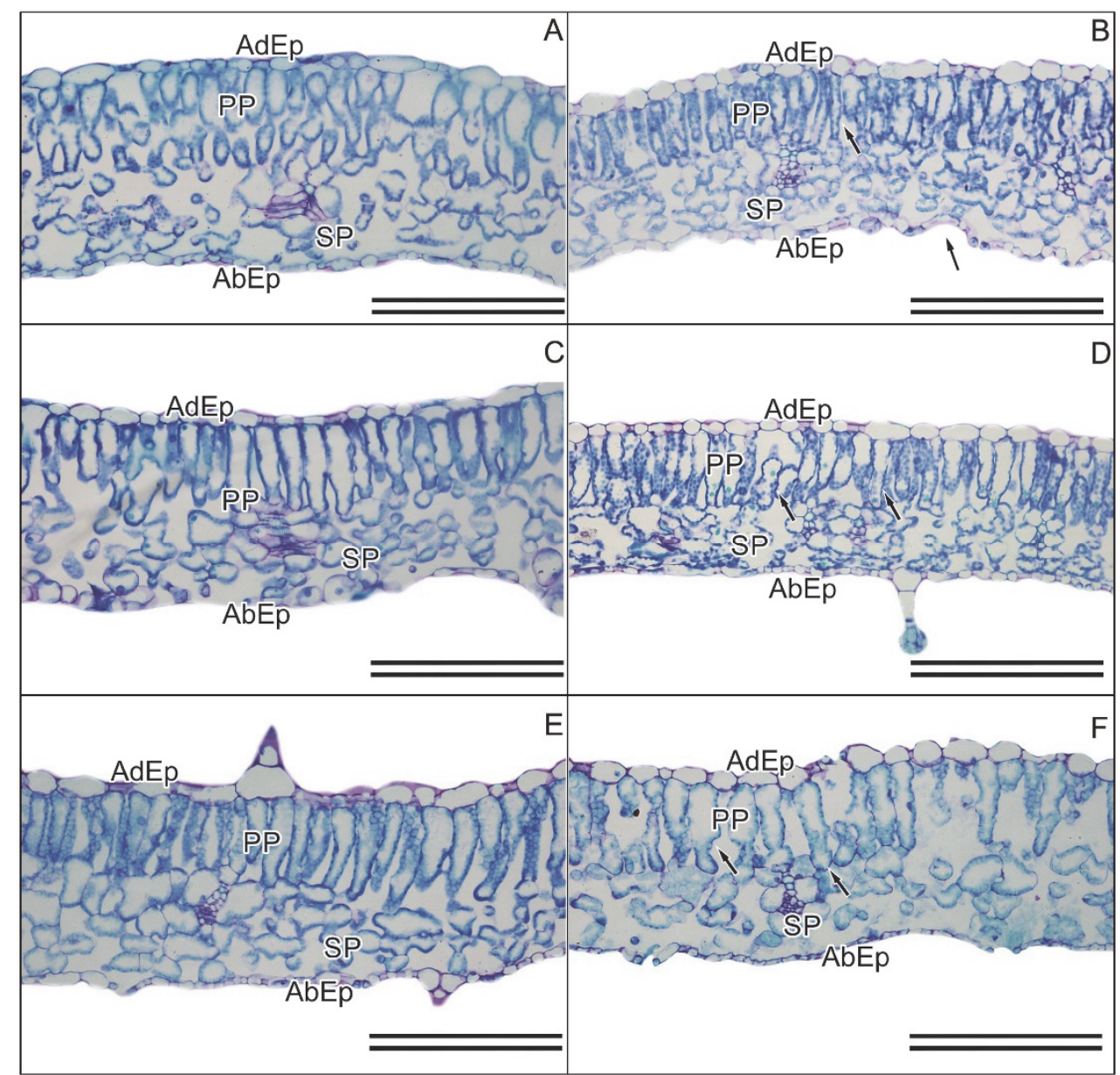

Fig. 6. Anatomical changes in response to heat stress in tomato leaves: the wild type cultivar Micro-Tom (MT; $A, B)$ and mutants high-pigment 1 ( $h p 1 ; C, D)$, and aurea (au; E,F) exposed to $25^{\circ} \mathrm{C}(A, C, E)$ and $42{ }^{\circ} \mathrm{C}(B, D, F)$ for 7 days. (AdEp - adaxial epidermis, AbEp - abaxial epidermis, PP - palisade parenchyma, SP - spongy parenchyma. Arrows indicate the cell collapse and mesophyll retraction. Scale bars: $200 \mu \mathrm{m}$.

Increasing NPQ is linked to the photoprotective capacity of plants (Müller et al. 2001). Thus, impairments induced by high temperature require another protective mechanism against an excessive radiation to prevent photooxidative damage. In this regard, the increases in $\mathrm{F}_{\mathrm{o}}$ in all the genotypes indicate that an excessive light energy was mostly dissipated by $\mathrm{Chl}$ fluorescence in the PS II light-harvesting antennae complex. The higher increases in $\mathrm{F}_{\mathrm{o}}$ in the $a u$ mutant highlight the role of phytochromes in plant tolerance to the heat stress since deficiency in the content of functional photoreceptor enhances the necessity of energy dissipation. This process carries a low energy to the photochemical stage of photosynthesis and causes losses in the au mutant.

Overall, our results suggest that a deficiency РФВ biosynthesis and the resulting decrease in the content of functional phytochromes enhanced the impairments in the photosynthetic performance of plants subjected to the heat stress, as shown by the $a u$ mutant responses at $42^{\circ} \mathrm{C}$. We also verified that the hyperresponsive phytochrome- 
mediated responses of the $h p l$ mutant corresponded to a higher efficiency in heat dissipation mechanisms. Consequently, $h p l$ presented a stable carbon assimilation even at high temperatures. The ability to dissipate heat via transpiration associated with the photosynthetic

\section{References}

Allakhverdiev, S.L., Kreslavski, V.D., Klimov, V.V., Los, D.A., Carpentier, R., Mohanty, P.: Heat stress: an overview of molecular responses in photosynthesis. - Photosynth. Res. 98: 541-550, 2008.

Alves, F.R.R., Melo, H.C., Crispim-Filho, A.J., Costa, A. C., Nascimento, K. J. T., Carvalho, R. F.: Physiological and biochemical responses of photomorphogenic tomato mutants (cv. Micro-Tom) under water withholding. - Acta Physiol. Plant. 38: 155, 2016.

Bianchetti, R.E., Cruz, A.B., Oliveira, B.S., Demarco, D., Purgatto, E., Peres, L.E.P., Rossi, M., Freschi, L.: Phytochromobilin deficiency impairs sugar metabolism through the regulation of cytokinin and auxin signaling in tomato fruits. - Sci. Rep. 7: 7822, 2017.

Bilger, W., Björkman, O.: Role of xanthophyll cycle in photoprotection elucidated by measurements of lightinduced absorbance changes, fluorescence and photosynthesis in leaves of Hedera canariensis. Photosynth. Res. 25: 173-185, 1990.

Bilger, W., Schreiber, U., Bock, M.: Determination of the quantum efficiency of photosystem II and of nonphotochemical quenching of chlorophyll fluorescence in the field. - Oecologia 102: 425-432, 1995.

Boccalandro, H.E., Ploschuk, E.L., Yanovsky, M.J., Sanchez, C.G., Casal, J.J.: Increased phytochrome B alleviates density effects on tuber yield of field potato crops. - Plant Physiol. 133: 1539-1546, 2003.

Boccalandro, H.E., Rugnone, M.L., Moreno, J.E., Ploschuk, E.L., Serna, L., Yanovsky, M.J., Casal, J.J.: Phytochrome B enhances photosynthesis at the expense of water-use efficiency in Arabidopsis. - Plant Physiol. 150: 1083-1092, 2009.

Carvalho, R.F., Campos, M.L., Azevedo, R.A.: The role of phytochrome in stress tolerance. - J. integr. Plant Biol. 53: 920-929, 2011a.

Carvalho, R.F., Campos, M.L., Pino, L.E., Crestana, S.L., Zsögön, A., Lima, J.E., Benedito, V.A., Peres, L.E.: Convergence of developmental mutants into a single tomato model system: 'Micro-Tom' as an effective toolkit for plant developmental research. - Plant Methods 7: 18, $2011 \mathrm{~b}$.

Chen, C., Xiao, Y., Li, X., Ni, M.: Light-regulated stomatal aperture in Arabidopsis. - Mol. Plants 5: 566-572, 2012.

Crafts-Brandner, S.J., Salvucci, M.E.: Rubisco activase constrains the photosynthetic potential of leaves at high temperature and $\mathrm{CO}_{2}$. - Proc. nat. Acad. Sci. USA 97: 13430-13435, 2000.

Doupis, G., Bertaki, M., Psarras, G., Kasapakis, I., Chartzoulakis, K.: Water relations, physiological behavior and antioxidant defence mechanism of olive plants subjected to different irrigation regimes. - Sci. Hort. 153: 150-156, 2013.

Ferreira-Silva, S.L., Voigt, E.L., Silva, E.M., Maia, J.M., Fontenele, A.V., Silveira, J.A.G.: High temperature positively modulates oxidative protection in salt-stressed cashew plants. - Environ. exp. Bot. 74: 162-170, 2011. performance was a determining factor for a greater tolerance of the tomato plants to the heat stress. However, in-depth studies should be carried out to further elucidate the genetic and molecular mechanisms.

Galmés, J., Kapralov, M.V., Copolovici, L.O., Hermida-Carrera C., Niinemets, Ü.: Temperature responses of the Rubisco maximum carboxylase activity across domains of life: phylogenetic signals, trade-offs, and importance for carbon gain. - Photosynth. Res. 123: 183-201, 2015.

Genty, B., Briantais, J.M., Baker, N.R.: The relationship between the quantum yield of photosynthetic electron transport and quenching of chlorophyll fluorescence. Biochim. biophys. Acta 990: 87-92, 1989.

Gerganova, M., Popova, A.V., Stanoeva, D., Velitchkova, M.: Tomato plants acclimate better to elevated temperature and high light than to treatment with each factor separately. Plant Physiol. Biochem. 104: 234-241, 2016.

Goud, K.V., Sharma, R.: Retention of photoinduction of cytosolic enzymes in aurea mutant of tomato (Lycopersicon esculentum). - Plant Physiol. 105: 643-650, 1994.

Goud, K.V, Sharma, R., Kendrick, R.E., Furuya, M.: Photoregulation of phenylalanine ammonia lyase is not correlated with anthocyanin induction in photomorphogenetic mutants of tomato (Lycopersicon esculentum). Plant Cell Physiol. 32: 1251-1258, 1991.

Grover, A., Mittal, D., Negi, M., Lavania, D.: Generating high temperature tolerant transgenic plants: achievements and challenges. - Plant Sci. 205-206: 38-47, 2013.

Ingraham, R.H., Lau, S.Y.M., Taneja, A.K., Hodges, R.S.: Denaturation and the effects of temperature on hydrophobic-interaction and reversed-phase highperformance liquid chromatography of proteins: Bio-gel tsk-phenyl-5-pw column. - J. Chromatogr. 327: 77-92, 1985.

Kalaji, H.M., Schansker, G., Ladle, R.J., Goltsev, V., Bosa, K., Allakhverdiev, S.I., Brestic, M., Bussotti, F., Calatayud, A., Dąbrowski, P., Elsheery, N.I., Ferroni, L., Guidi, L., Hogewoning, S.W., Jajoo, A., Misra, A.N., Nebauer, S.G., Pancaldi, S., Penella, C., Poli, D., Pollastrini, M., Romanowska-Duda, Z.B., Rutkowska, B., Serôdio, J., Suresh, K., Szulc, W., Tambussi, E., Yanniccari, M., Zivcak, M.: Frequently asked questions about in vivo chlorophyll fluorescence: practical issue. - Photosynth. Res. 122: 121-158, 2014.

Karnovsky, M.J.: A formaldehyde-glutaraldehyde fixative of high osmolarity for use in electron microscopy. - J. cell. Biol. 27: 137-138, 1965.

Khudyakova, A.Y., Kreslavski, V.D., Shirshikova, G.N., Zharmukhamedov, S.K., Kosobryukhov, A.A., Allakhverdiev, S.I.: Resistance of Arabidopsis thaliana L. photosynthetic apparatus to UV-B is reduced by deficit of phytochromes B and A. - J. Photochem. Photobiol. B 169: 41-46, 2017.

Kreslavski, V.D., Carpentier, R., Klimov, V.V., Murata, N., Allakhverdiev, S.I.: Molecular mechanisms of stress resistance of the photosynthetic apparatus. - Biochem. (Moscow) 1 Suppl. Ser. A: 185-205, 2007.

Krüger, T.P.J., Ilioaia, C., Johnson, M.P., Ruban, A.V., Grondelle, R.V.: Disentangling the low-energy states of the 
major light-harvesting complex of plants and their role in photoprotection. - Biochim. biophys. Acta 1837: 10271038, 2014.

Latif, H.H., Mohamed, H.I.: Exogenous applications of moringa leaf extract effect on retrotransposon, ultrastructural and biochemical contents of common bean plants under environmental stresses. - S. Afr. J. Bot. 106: 221-231, 2016.

Liu, Y., Roof, S., Ye, Z., Barry, C., Tuinen, A.V., Vrebalov, J., Bowler, C., Giovannoni, J.: Manipulation of light signal transduction as a means of modifying fruit nutritional quality in tomato. - Proc. nat. Acad. Sci. USA 101: $9897-$ 9902, 2004

Lubovská, Z., Dobrá, J., Štorchová, H., Wilhelmová, N., Vanková, R.: Cytokinin oxidase/dehydrogenase overexpression modifies antioxidant defense against heat, drought and their combination in Nicotiana tabacum plants. - J. Plant Physiol. 171: 1625-1633, 2014.

Mathur, S., Agrawal, D., Jajoo, A.: Photosynthesis: response to high temperature stress. - J. Photochem. Photobiol. B. 137: 116-126, 2014.

McCormac, A.C., Fischer, A., Kumar, A.M., Söll, D., Terry, M.J.: Regulation of HEMAl expression by phytochrome and a plastid signal during de-etiolation in Arabidopsis thaliana. - Plant. J. 25: 549-561, 2001.

Melo, H.C., Castro, E.M., Alves, E., Perina, F.J.: [Leaf anatomy of micro-tomato phytochrome-mutants and chloroplast ultra-structure]. - Ciênc. Agrotec. 35: 11-18, 2011. [In Port.]

Meneguelli-Souza, A.C., Vitória, A.P., Vieira, T.O., DegliEsposti, M.S.O., Souza, C.M.M.: Ecophysiological responses of Eichhornia crassipes (Mart.) Solms to $\mathrm{As}^{5+}$ under different stress conditions. - Photosynthetica 54: 243250, 2016.

Merzlyak, M.N., Solovchenko, A.E.: Photostability of pigments in ripening apple fruit: a possible photoprotective role of carotenoids during plant senescence. - Plant Sci. 163: 881$888,2002$.

Moon, J., Zhu, L., Shen, H., Huq, E.: PIF1 directly and indirectly regulates chlorophyll biosynthesis to optimize the greening process in Arabidopsis. - Proc. nat. Acad. Sci. USA 105: 9433-9438, 2008.

Müller, P., Li, X., Niyogi, K.K.: Non-photochemical quenching. A response to excess light energy. - Plant Physiol. 125: 1558-1566, 2001

Muramoto, T., Kami, C., Kataoka, H., Iwata, N., Linley, P.J., Mukougawa, K., Yokota, A., Kohchi, T.: The tomato photomorphogenetic mutant aurea is deficient in phytochromobilin synthase for phytochrome chromophore biosynthesis. - Plant Cell Physiol. 46: 661-665, 2005.

Murchie, E.H., Horton, P.: Acclimation of photosynthesis to irradiance and spectral quality in British plant species: chlorophyll content, photosynthetic capacity and habitat preference. - Plant Cell Environ. 20: 438-448, 1997.

Mutava, R.N., Prince, S.J.K., Syed, N.H., Song, L., Valliyodan, B., Chen, W., Nguyen, H.T.: Understanding abiotic stress tolerance mechanisms in soybean: A comparative evaluation of soybean response to drought and flooding stress. - Plant Physiol. Biochem. 86: 109-120, 2015.

O'brien, T.P., Feder, N., Mccully, M.E.: Polychromatic staining of plant cell walls by toluidine blue O. - Protoplasma 59: 368-373, 1964
Peters, J.L., Széll, M., Kendrick, R.E.: The expression of lightregulated genes in the high-pigment-1 mutant of tomato. Plant Physiol. 117: 797-807, 1998.

Possart, A., Fleck, C., Hiltbrunner, A.: Shedding (far-red) light on phytochrome mechanisms and responses in land plants. Plant Sci. 217-218: 36-46, 2014.

Rizhsky, L., Liang, H., Mittler, R.: The combined effect of drought stress and heat shock on gene expression in tobacco. - Plant Physiol. 130: 1143-1151, 2002.

Sajid, M., Rashid, B., Ali, Q., Husnain, T.: Mechanisms of heat sensing and responses in plants. It is not all about $\mathrm{Ca}^{2+}$ ions. - Biol. Plant. 62: 409-420, 2018.

Salvucci, M.E., Crafts-Brandner, S.J.: Relationship between the heat tolerance of photosynthesis and the thermal stability of Rubisco activase in plants from contrasting thermal environments. - Plant Physiol. 134: 1460-1470, 2004.

Schittenhelm, S., Menge-Hartmann, U., Oldenburg, E.: Photosynthesis, carbohydrate metabolism, and yield of phytochrome-B-overexpressing potatoes under different light regimes. - Crop Sci. 44: 131-143, 2004.

Scholander, P.F., Hammel, H.T., Bradstreet, E.D., Hemmingsen, E.A.: Sap pressure in vascular plants: negative hydrostatic pressure can be measured in plants. - Science 148: 339-346, 1965.

Sharma, L., Priya, M., Bindumadhava, H., Nair, R.M., Nayyar, H.: Influence of high temperature stress on growth, phenology and yield performance of mungbean [Vigna radiata (L.) Wilczek] under managed growth conditions. Sci. Hort. 213: 379-391, 2016.

Soto, A., Hernández, L., Quiles, M.J.: High root temperature affects the tolerance to high light intensity in Spathiphyllum plants. - Plant Sci. 227: 84-89, 2014.

Terry, M.J., Kendrick, R.E.: The aurea and yellow-green-2 mutants of tomato are deficient in phytochrome chromophore synthesis. - J. Biol. Chem. 271: 21681-21686, 1996.

Teskey, R., Wertin, T., Bauweraerts, I., Ameye, M., Mcguire, M.A., Steppe, K.: Responses of tree species to heat waves and extreme heat events. - Plant Cell Environ. 38: 16991712, 2014.

Wang, F.F., Lian, H., Kang, C., Yang, H.: Phytochrome B is involved in mediating red light-induced stomatal opening in Arabidopsis thaliana. - Mol. Plant 3: 246-259, 2010.

Wellburn, A.R.: The spectral determination of chlorophylls $a$ and $b$, as well as total carotenoids, using various solvents with spectrophotometers of different resolution. - J. Plant Physiol. 144: 307-313, 1997.

Zhang, G.L., Chen, L.Y., Zhang, S.T., Zheng, H., Liu, G.H. Effects of high temperature stress on microscopic and ultrastructural characteristics of mesophyll cells in flag leaves of rice. - Rice Sci. 16: 65-71, 2009.

Zhang, J., Stankey, R.J., Vierstra, R.D.: Structure-guided engineering of plant phytochrome B with altered photochemistry and light signaling. - Plant Physiol. 161: 1445-1457, 2013.

Zhou, S., Sun, H., Zheng, B., Li, R., Zangh, W.: Cell cycle transcription factor E2F2 mediates non-stress temperature response of AtHSP70-4 in Arabidopsis. - Biochem. biophys. Res. Commun. 455: 139-146, 2014. 